\title{
La pêche à Terre-Neuve et le commerce international : deux activités complémentaires au XVIe siècle
}

Fishing in Newfoundland and international commerce: two complementary activities in the sixteenth century

\section{Hilario Casado Alonso}

\section{(2) OpenEdition} Journals

\section{Édition électronique}

URL : http://journals.openedition.org/abpo/2622

DOI : $10.4000 / a b p o .2622$

ISBN : 978-2-7535-2843-7

ISSN : 2108-6443

\section{Éditeur}

Presses universitaires de Rennes

\section{Édition imprimée}

Date de publication : 30 juin 2013

Pagination : 111-132

ISBN : 978-2-7535-2838-3

ISSN : 0399-0826

\section{Référence électronique}

Hilario Casado Alonso, "La pêche à Terre-Neuve et le commerce international : deux activités complémentaires au XVle siècle », Annales de Bretagne et des Pays de l'Ouest [En ligne], 120-2 | 2013, mis en ligne le 20 juin 2015, consulté le 01 mai 2019. URL : http://journals.openedition.org/abpo/2622 ; DOI : 10.4000/abpo.2622 


\title{
La pêche à Terre-Neuve et le commerce international : deux activités complémen- taires au XVI ${ }^{\mathrm{e}}$ siècle $^{1}$
}

\author{
Hilario CASADO ALONSO \\ Université de Valladolid
}

La somme des recherches consacrées à la pêche à Terre-Neuve et au Labrador forme aujourd'hui un chapitre à part dans la bibliographie de l'histoire maritime mondiale ${ }^{2}$. Nous savons qu'à partir des premières années du $\mathrm{XVI}^{\mathrm{e}}$ siècle, la pêche européenne commença à investir les eaux canadiennes pour capturer de la morue et chasser des cétacés. Les pêcheurs portugais, normands et bretons maintenaient une activité modeste mais régulière dans ces eaux. À partir des années 1520, les marins du Pays basque français et certainement d'Espagne se joignirent à eux, et rapidement ils supplantèrent leurs prédécesseurs ${ }^{3}$, si bien que, dès le milieu du siècle, cette pêche transatlantique pratiquée par les Biscaïens, les marins de Guipúzcoa et les

1. Ce travail a été réalisé dans le cadre des projets «Empresas y empresarios en Castilla y León (siglos XVI-XX) ", subventionné par la Junta de Castilla y León (Ref. VA050A06), et " Dynamic Complexity of Cooperation-Based Self-Organizing Networks in the First Global Age (DynCoopNet) ", subventionné par la European Science Foundation au titre du programme EUROCORES (Ref. 06-TECT-FP-004).

2. Mollat du Jourdin, Michel (dir.), Histoire des pêches maritimes en France, Toulouse, Privat, 1987. Cell, G. T., English Enterprise in Newfoundland, 1577-1660, Toronto, University of Toronto Press, 1969. LA MoRAndière, Charles de, Histoire française de la pêche à la morue en Amérique septentrionale (des origines à 1789), Paris, Maisonneuve et Larose, 1962. ADAms InNIS, Harold, The Cod Fisheries: the History of An International Economy, Toronto, University of Toronto Press, 1954.

3. Belanger, René, Les Basques dans l'estuaire du Saint-Laurent, 1535-1635, Montréal, Presses de l'Université du Québec, 1971. AzPIAZu ElorzA, Jose Antonio, "La pesca del bacalao, su preparación y comercialización en Guipúzcoa en la Alta Edad Moderna ", Anuario del Instituto de Estudios Marítimos Juan de la Cosa, n 7, 1988-1998, p. 85-110. AzPiazu Elorza, Jose Antonio, Balleneros vascos en el Cantábrico, San Sebastián, Estudios, 2000. Bourgoin, Jean, Carpine-LAncre, Jacqueline, (éd.), L'Aventure maritime, du golfe de Gascogne à Terre-Neuve, $118^{\mathrm{e}}$ congrès national des sociétés historiques et scientifiques (Pau, 1993), Paris, Éditions du CTHS, 1995. TuRGEON, Laurier, « Pêches basques du Labourd en Atlantique nord (xvl -xvIl ${ }^{\mathrm{e}}$ siècles) : ports routes et trafics ", Itsas memoria. Revista de estudios marítimos del País Vasco, n 3, 2000, p. 163-178. 
Basques français atteignit son apogée. Des améliorations dans les techniques navales, avec une augmentation de la rentabilité économique des produits obtenus - l'huile de baleine et les morues salées - suscitèrent un intérêt croissant de la part des investisseurs, des patrons et des marins pour cette pêche en haute mer, ce qui se traduisit par une augmentation du nombre de bateaux expédiés vers ces eaux à diverses époques de l'année. Dans le cas espagnol, S. Huxley et M. Barkham, les meilleurs spécialistes de ces exploitations de pêche, signalent que la flotte hispano-basque de TerreNeuve disposait annuellement, de 1559 à 1585, d'environ 40 bateaux (de 20 à 25 pour la pêche à la morue et de 15 à 20 pour la chasse à la baleine), soit une capacité de quelque 9500 tonneaux ${ }^{4}$. Ce fut l'époque de la splendeur avant que ne commence une crise progressive au cours de laquelle la flotte basque et celle du golfe de Gascogne furent dépassées par d'autres concurrents.

La plupart des travaux publiés sur le thème de la pêche exercée par les différentes flottes européennes à Terre-Neuve et au Labrador et de leurs industries navales connexes partent d'une prémisse : les bateaux et les hommes qui pratiquaient la capture de la morue et de la baleine dans les eaux canadiennes se consacraient de façon presque exclusive à ces activités. Il aurait ainsi existé une certaine spécialisation des bâtiments de pêche à cette époque. S'il s'agit effectivement d'une réalité contemporaine, les flottes de pêche et de commerce étant aujourd'hui très différentes, cela ne paraît toutefois pas une évidence pour des temps plus reculés. Il convient donc de s'interroger sur les usages faits des navires terre-neuvas au XVI ${ }^{\mathrm{e}}$ siècle.

L'objectif de cet article est de montrer comment, tout du moins pour le $\mathrm{XVI}^{\mathrm{e}}$ siècle, la pêche était en réalité indissociable du commerce. Pour les navires comme pour les patrons, les maîtres et les marins, les campagnes à Terre-Neuve alternaient avec les expéditions commerciales et le transport international sur d'autres routes. Comme nous le verrons, cette complémentarité ressortissait à la nécessité de disposer des liquidités indispensables au financement de la plupart des voyages vers les eaux canadiennes. Bien souvent, un même bâtiment pratiquait alternativement, pendant des mois ou des années, la pêche, le commerce et le transport à longue distance. C'est pourquoi je crois qu'au Xvi ${ }^{\mathrm{e}}$ siècle on ne peut parler

4. HuXley, Selma, "Los Vascos y las pesquerías transatlánticas, 1517-1713 ", AYERBE, E. (dir.), Itsasoa 3. Los vascos en el marco Atlántico norte. Siglos XVI y XVII, San Sebastián, Etor, 1987, p. 26-210. HuXLEy, Selma, "Aperçu de l'évolution de la pêche sur les côtes de l'Est canadien ", L'Aventure maritime..., op. cit., p. 175-180. HuXLEY, Selma, Michael BARKHAM, Michael, "Los Arriola de Urazandi : iniciativa empresarial marítima en Vizcaya y Guipúzcoa (c. 1540-c. 1630)", Itsas memoria. Revista de estudios marítimos del País Vasco, $\mathrm{n}^{\circ}$ 1, 1996, p. 349-388. BARKHAM, Michael, Shipowning, Shipbuilding ans Trans-Atlantic Fishing in Spanish Basque Ports, 1560-1630 : a Case Study of Motrico ans Zumaya, thèse de doctorat, Université de Cambridge, 1990. BARKHAM, Michael, «La industria pesquera en el País Vasco peninsular al principio de la Edad Moderna : ¿Una edad de oro? ", Itsas memoria. Revista de estudios marítimos del País Vasco, n 3, 2000, p. 29-75. 
d'une spécialisation de la pêche de la part des flottes espagnole, portugaise et franco-basque. Au contraire, la documentation employée, formée de milliers de polices d'assurances maritimes de Burgos, montre la grande complémentarité qui existait alors entre les activités marchandes et la pêche en haute mer.

\section{Les assurances maritimes de Burgos : observatoire de la pêche à Terre-Neuve au $\mathrm{XVI}^{\mathrm{e}}$ siècle}

Bien que l'on ait conservé des données sur les assurances maritimes depuis la fin du Xv ${ }^{e}$ siècle, ce n'est qu'à partir du milieu du siècle suivant que le Consulat de Burgos les enregistra systématiquement. Certes, nous ne disposons que de 10396 polices, ce qui n'est qu'une modeste fraction du corpus originel ${ }^{5}$. Cependant, pour la période antérieure au XVIII ${ }^{\mathrm{e}}$ siècle, cette quantité est la plus importante qui soit disponible au sein des archives européennes. À ce titre, la documentation burgalaise procure une somme d'informations considérable pour la connaissance de l'histoire de l'assurance et donc de l'histoire navale de l'Europe. Précisément, les registres de polices couvrent la période comprise entre 1565 et 1619. Sur le total de 10396 actes qu'ils contiennent, la majorité - soit 8195 - concerne les années 1565-1573. Un si grand nombre de polices concentré sur une période aussi courte permet d'étudier précisément tout à la fois la navigation, le commerce et la pêche. J'ai pu individualiser 4743 expéditions de bateaux assurées à Burgos entre les années 1565 et 1619. En dehors des expéditions de pêche à Terre-Neuve, les routes évoquées dans ces contrats d'assurance maritime sont nombreuses. Certaines participent à l'intense commerce de cabotage joignant, par le Portugal, les côtes du golfe de Gascogne à Séville. D'autres conduisent jusqu'à l'Amérique espagnole et au Brésil. Les routes atlantiques vers les anciens Pays-Bas, l'Angleterre, la France et l'Allemagne et même la Baltique y sont aussi présentes, comme celles qui liaient par un trafic soutenu les côtes espagnoles et italiennes. Enfin, dans une moindre mesure, l'on rencontre le commerce tissé entre l'Afrique et la péninsule ibérique et l'Amérique, ainsi que les routes de l'Inde. Ces expéditions employaient des maîtres et des bateaux de tout type, originaires des marines basque, cantabre, bretonne, flamande, hollandaise, de Raguse, hanséatique, portugaise, andalouse, galicienne, anglaise, catalane, génoise et bordelaise ${ }^{6}$.

5. Archivo de la Diputación Provincial de Burgos, Consulado. Libros 28, 37, 39, 41, 44, 46, 74, 95, 98, 99 et 101 .

6. CASADo Alonso, Hilario, "Comercio Internacional y Seguros Marítimos en Burgos en la época de los Reyes Católicos ", Bartolomeu Dias e a sua epoca, actes du congrès, Oporto, Universidad, 1990. p. 221-238. CASADO ALONSO, Hilario, " El mercado internacional de seguros de Burgos en el siglo XVI ", Boletín de la Institución Fernán González, année LXXVIII, nº 219, 1999/2, p. 277-306. CASADO AlONSO, Hilario, "El comercio de hierro vasco visto a través de los seguros marítimos burgaleses (1565-1596) ", Itsas Memoria. Revista de Estudios marítimos del País Vasco, n 4, 2003, p. 165-192. CASADO Alonso, Hilario, « Los 
Parmi ce grand ensemble d'assurances burgalaises, 415 se rapportent à la pêche à Terre-Neuve et totalisent un montant de 213973 ducats ${ }^{7}$. Les aléas archivistiques ont voulu que la plupart des contrats conservés datent des années 1565-1572. Aussi, il ne faudrait pas en conclure que pendant les années postérieures il y eut moins de voyages à Terre-Neuve ou que ceux-ci furent assurés dans un autre lieu. Les polices étaient contractées de différentes manières, selon la répartition des investissements réalisés par les organisateurs de l'expédition. Le plus souvent, on prenait deux polices différentes, l'une sur la coque, l'artillerie et les munitions, l'autre sur l'équipement (hameçons, harpons, chaudières, filets), l'avitaillement (biscuits, vin, cidre, sel, barriques et autres vivres) et la pêche obtenue (poisson salé et à l'huile). Dans d'autres cas, l'assurance portait sur l'argent prêté aux maîtres pour acheter les équipements. Il était aussi fréquent de signer une police sur le voyage d'aller et une autre sur celui de retour, quoiqu'il ne soit pas rare que toute la route soit couverte par un même contrat. Plus rarement, le risque était réparti en trois ou quatre polices (tableau $\mathrm{n}^{\circ} 1$, annexes). Les polices permettent également de distinguer les types de pêche exercée lors de ces expéditions. Leur analyse détaillée indique que la capture des morues supplante en nombre de contrats la prise des baleines. Cependant, les sommes engagées pour cette dernière activité sont supérieures à celles relatives à la première. Ce fait réaffirme ce que d'autres auteurs ont signalé : la pêche baleinière exigeait de plus grands investissements que celle de la morue ${ }^{8}$.

Les 415 contrats recensés se rapportent à l'assurance de 263 expéditions pour Terre-Neuve, l'année 1572 étant celle durant laquelle il y eut le plus grand nombre de campagnes de pêche (annexe 2$)^{9}$. Dans la plupart des cas, le départ du voyage se faisait depuis les ports de la côte du golfe de Gascogne, d'Avilés à Fuenterrabía, jusqu'à Capbreton. Saint-Sébastien arrive en tête, suivi de Deva et des ports du Pays basque français (Bayonne, Saint-Jean-de-Luz et Ciboure). Ensuite, viennent les ports biscaïens - Bilbao et Portugalete notamment - et ceux de Cantabrie comme Laredo. Signalons enfin la présence singulière de la flotte portugaise de Viana do Castelo. Les ports d'attache des navires employés pour les campagnes de pêche étaient souvent ceux à partir desquels étaient lancées les expéditions.

seguros marítimos de Burgos. Observatorio del comercio internacional portugués en el siglo XVI ", Revista da Faculdade de Letras. História. Porto, $3^{\mathrm{e}}$ série, vol. 4, 2003, p. 213-242.

7. HuXLEY, Selma, "Burgos Insurance for Basque Ships: Maritime Policies from Spain, 1547-1592 ", Archivaria, 11, 1980-1981, p. 87-99. BARKHAM, Michael, " Mercaderes, comercio y finanzas en el norte de España: el seguro marítimo en Burgos y su desarrollo en S. Sebastián, Bilbao y Madrid (1500-1630) ", Actas del V Centenario del Consulado de Burgos, Burgos, 1994, vol. I, p. 557-619.

8. Dans certains cas, celle-ci n'est pas très définie, ce qui fait penser qu'ils alternèrent les deux types d'activité. J'ai signalé celle qui m'a semblé la plus remarquable. La plupart des polices aux buts inconnus sont des assurances sur l'argent prêté aux maîtres pour armer les embarcations.

9. Pour leur calcul, j'ai regroupé en une seule quantité les expéditions où l'aller et le retour furent assurés. 


\section{Origine des navires terre-neuviers dont les cargaisons ont été assurées à Burgos (1565-1615)}

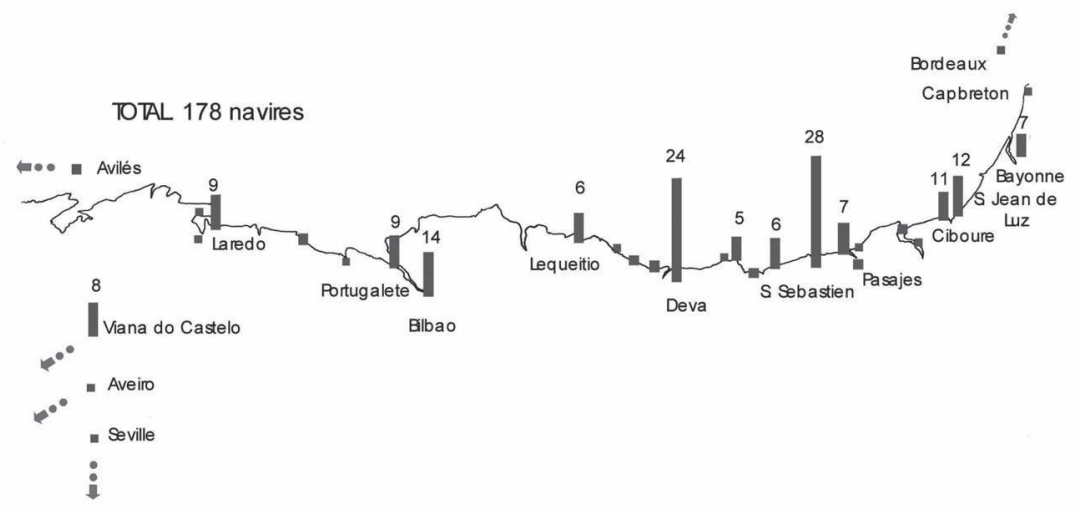

Beaucoup de ces bateaux n'apparaissent qu'occasionnellement, tandis que d'autres étaient affectés régulièrement aux itinéraires terre-neuviers. J'ai inventorié 178 bateaux différents, en fonction de leur type, de leur nom, de leur patron et de leur maître. Ils provenaient de Guipúzcoa, de Biscaye, de Santander, du Pays basque français et du Portugal. Il faut remarquer qu'aucune police ne se rapporte à un bateau breton ou anglais, alors qu'on les sait très actifs à cette époque à Terre-Neuve; ils étaient logiquement assurés dans leurs territoires respectifs. À propos du type de bateaux utilisés dans cette pêche hauturière, pour la plupart les polices précisent qu'il s'agissait de galions et de nefs, sauf dans quelques rares cas où l'on parle d'une " zabra " et de deux galéasses.

Si l'on considère enfin l'origine des parties contractantes, 49 localités différentes sont mentionnées (annexe 3). Comme il est naturel, celles qui prédominent sont celles de Guipúzcoa - spécialement Saint-Sébastien, Deva, Rentería et Eibar - suivies de celles de Biscaye et du Pays basque français. Vient ensuite un éventail de multiples localités. Les contractants sont en général des patrons de bateaux qui participaient à la pêche en haute mer, et qui pouvaient être aussi propriétaires de forges, fabricants d'armes ou commerçants. Ils composaient la classe entreprenante et florissante qui prospéra et s'enrichit au Pays basque et en Cantabrie pendant le règne de Philippe II. Parmi les quelques cas remarquables et très connus, signalons Juan de Portu, Miguel de Beroiz, Baltasar de Lerchundi, Martín et Esteban de Santiago, originaires de Saint-Sébastien; Martín Ochoa de Irrazazabal et Domingo de Sorasu, originaires de Deva; María de Uranzo et Sebastián de Zubieta, originaires de Rentería; Juan Pérez de Ocariz de Mondragón; Domingo de Villaviciosa de Pasajes; Andrés de Arrizabalaga et Martín López de Isasi, originaires de Eibar; Tomás de Esparza de Fuenterrabía; Francisco Cachopín de Laredo; Melchor et 
Martín de Alzaga de Portugalete; Auger de Barcos de Bayonne; Martinón, Juan et Pedro de Sociondo de Saint-Jean-de-Luz. La forte rentabilité économique des expéditions terre-neuvières attirait des capitaux provenant d'autres secteurs que la pêche. Les investissements n'étaient donc pas réservés aux gens de mer, mais relevaient aussi de commerçants, de fabricants d'armes, et même de membres des dynasties locales, à la tête de grandes entreprises, qui voyaient dans la capture des morues et des baleines le moyen de diversifier leurs affaires. Ce fait nous amène à nous demander s'il y avait à cette époque une complémentarité entre la pêche et le commerce international.

\section{La complémentarité entre la pêche à Terre-Neuve et le commerce international}

Comme je l'ai signalé en introduction, l'histoire de la pêche repose sur un postulat implicite selon lequel elle aurait été l'occupation exclusive de ses acteurs. Tout au plus, il est dit que les pêcheurs étaient parfois aussi agriculteurs. C'est le cas des différentes études sur les confréries de pêcheurs de beaucoup de villes côtières basques. Quand l'objectif est d'analyser la pêche hauturière, par exemple celle qui se pratiquait dans les eaux de Terre-Neuve, la plupart des chercheurs ne signalent pas si les patrons, maîtres ou marins travaillaient aussi dans d'autres secteurs. Cette façon d'aborder le problème peut amener le lecteur à en conclure que la pêche et le commerce international étaient deux activités complètement différenciées. Il est vrai que cette distinction était valable pour les bateaux, certains étant exclusivement consacrés à la pêche, d'autres au commerce, comme c'est le cas aujourd'hui.

Cette conception ne résiste pas à l'étude des polices d'assurances maritimes de Burgos. En rapprochant les 415 contrats signés pour la pêche à Terre-Neuve des milliers d'autres assurances, il est possible de reconstruire, année par année, une partie des itinéraires et des activités des navires. Nous appuyant simplement sur les données relatives au nom de chaque bateau, à sa provenance, à son maître et à son patron, on peut suivre quelles furent certaines des opérations et des routes auxquelles il participa. Il nous faut cependant immédiatement relativiser la portée de ce travail d'analyse et de reconstitution. Ces données sont a priori incomplètes puisqu'elles ne concernent que les expéditions ayant fait l'objet d'un contrat d'assurance; tous les mouvements non contractuels nous échappent. De plus, l'histoire individuelle des bâtiments ne nous est connue que de façon partielle, vu qu'il n'était pas rare qu'ils changent de nom et de maître au cours de leur existence. Ainsi, il est probable que des bateaux décrits dans les documents sous des identités différentes correspondent en réalité à un seul et même spécimen. Faute de sources complémentaires comme les immatriculations de bateaux, les registres de douanes ou d'impôts d'avaries, il n'est donc pas possible de préciser davantage l'histoire 
des navires. Mais ce travail est impossible pour d'autres ports et flottes totalement privés de ce type de documents.

Sur les 178 bateaux ayant été assurés au moins une fois entre 1565 et 1615 pour se rendre à Terre-Neuve, 71 furent également employés en dehors d'expéditions de pêche. Un même bâtiment peut apparaître dans des actes successifs, contractés par des acteurs différents ou non et couvrant des trajets vers le Canada ainsi que vers d'autres destinations. Plusieurs observations ressortent des données rassemblées dans l'annexe 4. D'abord, pour une série de bateaux, on eut recours au commerce dans les ports escales du parcours pour financer l'expédition vers Terre-Neuve. Comme S. Huxley l'a déjà fait remarquer, très souvent le voyage des côtes du golfe de Biscaye jusqu'au Canada n'était pas effectué en droiture mais empruntait un itinéraire marqué d'arrêts intermédiaires pour s'approvisionner de tout ce dont on avait besoin pour la pêche. Quelquefois, ces escales sont indiquées sur la police d'assurance principale, mais à d'autres reprises elles figurent sur des contrats différents, ce qui ferait penser à première vue qu'il s'agit d'autres expéditions. Trois voies indirectes étaient alors privilégiées pour se rendre à Terre-Neuve : la côte basque - La Rochelle/Nantes - Terre-Neuve; la côte basque - le Portugal - Terre-Neuve; la côte basque - Séville - Terre-Neuve. La première avait notamment pour but d'acheter l'équipement et l'attirail nécessaires pour la pêche : biscuit, vin, hameçons, harpons et filets. Les deux autres (par Aveiro, Lisbonne, Setúbal ou Séville) servaient davantage à l'approvisionnement en sel, denrée nécessaire pour conserver la morue. Les navires ne se rendaient pas à vide dans ces ports d'escale. Ils partaient à La Rochelle et à Nantes chargés en général de laine et de fer qu'ils échangeaient. S'ils mettaient le cap sur le sud à la recherche du sel, c'est avec du fer, des objets ferreux et des armes. Ils côtoyaient alors les autres bâtiments qui, à cette époque, participaient à l'intense commerce de cabotage entre la côte du golfe de Gascogne, le Portugal et l'Andalousie.

À côté de ces opérations relativement élaborées, où se mêlaient et se complétaient la pêche, l'approvisionnement et le négoce, beaucoup d'autres se succédaient dans l'agenda du bateau pour des motifs très différents, sans aucun rapport entre eux. Pendant quelques mois, le navire accomplissait sa saison morutière ou baleinière; puis, de retour à son port d'attache et ayant déposé ses barriques de graisse et ses morues salées, il était aussitôt chargé de marchandises pour rejoindre une autre destination. Dans certains cas, un même bâtiment faisait ainsi deux ou trois expéditions dans l'année. Dans le même temps, il lui arrivait parfois de changer de patron et d'équipage. Étant donné la courte période renseignée par les polices disponibles, on regrette de ne pas pouvoir calculer la durée de vie utile des navires ni d'être en mesure de reconstituer l'usage qui en était fait tout au long de la seconde moitié du XVI ${ }^{\mathrm{e}}$ siècle.

Les polices de Burgos indiquent que les nefs, les galions et les "zabras " employés pour la pêche hauturière participaient simultanément aux multiples trafics qui partaient des ports de l'Atlantique, qu'ils fussent espagnols, 
français ou portugais. On les voit ainsi chargés de fer, d'objets ferreux, de sacs de laine, de cuirs, de tissus, d'épices, de sucre, de colorants et d'autres marchandises. Il n'est pas rare qu'ils fissent partie des flottes de la laine castillane à destination des Flandres, de la Normandie et de la Bretagne, ou des flottes portugaises de Viana do Castelo, chargés de sucre et de teintures du Brésil. Il existait donc une " pluri-utilisation » des bateaux, selon le besoin des affaires menées par les patrons et les autres financeurs des expéditions.

Six cas illustrent parfaitement ce phénomène. Le premier d'entre eux est celui du galion de Zumaya, La Trinidad, dont était maître Baltasar de Orio, habitant de Guetaria. Entre les mois de décembre 1567 et avril 1568, il voyagea de Zumaya à Séville chargé de fer, de ferrures, de clous, de houes, de haches et de brai, le tout assuré pour 10270 ducats et consigné au nom de divers marchands d'Elorrio, d'Azpeitia, d'Eibar, de Plasencia, d'Elgueta et de Séville. Parmi ces négociants, il faut signaler les Iturbe d'Elorrio et le fameux marchand d'Eibar, Martín López de Isasi. Durant l'hiver 1568-1569, le bâtiment prit la même route avec un chargement très semblable au précédent, dont la plus grande partie appartenait aux Lobiano, une famille basque installée à Séville; puis, en mars 1569, le bateau partit pour Terre-Neuve, Gregorio de Sorasu de Marquina assurant sa carcasse pour 300 ducats. Selon cet exemple, un navire pouvait être employé autant pour le commerce de fer basque à destination de l'Andalousie et de l'Amérique que pour la pêche en terre-neuviène.

Le Santa Cruz (Sainte-Croix), galion de Lequeitio, qui avait pour maîtres les frères Rodrigo et Juan de Legarza, était spécialement destiné à la pêche. Au printemps 1568, plusieurs habitants de Motrico assurèrent l'équipement et les vivres pour qu'il parte capturer des morues à Terre-Neuve. Nous ne savons pas ce qu'il fit en 1569, mais dans les premiers mois de 1570, plusieurs marchands de Marquina, Vitoria, Ermua, Elgueta et Séville assurèrent, pour une valeur de 3400 ducats, un chargement de fers, de haches et de clous, que ce bateau devait mener à Séville. En septembre de cette année-là, le " Santa Cruz ", désormais détenu par Martín Ibáñez de Sarasua, habitant de Marquina, était à Terre-Neuve. Son propriétaire assura sa coque pour 600 ducats et Pedro de Licona et Juan Arrechu son équipement pour 250 ducats, avant qu'il ne réalise son voyage de retour à Lequeitio. De novembre 1570 à janvier 1571, l'on devait préparer son départ pour Séville puisque différents marchands de Guipúzcoa assurèrent sa cargaison de fers, d'arquebuses et de diverses autres denrées. La date de son appareillage nous est inconnue mais le printemps suivant, il réapparaît dans deux polices contractées sur la coque par son propriétaire, Martín Ibáñez, auquel s'était associé Rodrigo de Legarza, le maître. L'opération prévoyait un premier trajet de Lequeitio à Séville, puis une traversée jusqu'à Terre-Neuve, et enfin un retour à Bilbao. En octobre 1571, il semble qu'il ait réitéré le même parcours avec un chargement identique, au départ cette fois-ci d'Ondárroa. Le voyage se répète au début de l'année 1572, la cargaison étant formée de fers et "d'angers " appartenant aux Urquizu d'Elorrio et aux Lobiano de Séville. Le bateau quitta ensuite l'Andalousie pour la 
Canada, les propriétaires assurant au retour de sa campagne morutière la coque et l'équipement naval. En somme, les itinéraires de ces deux galions rendent assez bien compte de l'utilisation du commerce du fer et d'autres objets ferreux entre le Pays basque et Séville pour financer les expéditions de pêche à Terre-Neuve.

Cette complémentarité apparaît plus évidente encore dans les pérégrinations de deux autres bâtiments. Prenons l'exemple de la Santa María (Sainte-Marie), nef de Viana do Castelo placée sous le commandement de Manuel Pita le jeune. Ce bateau, entre septembre et décembre 1567, navigua de Portimâo à Londres et à Anvers, faisant escale à Bayona de Galice, chargé de figues appartenant au marchand de Viana, Antonio Alvares Veigas. En mai 1568, il fut assuré pour partir à la pêche à la morue à Terre-Neuve. On ne sait pas ce qu'il fit l'année suivante. En juillet 1570, une police couvrit une nouvelle expédition morutière, complétée peut-être par la capture de baleines car l'acte cite des barriques de graisse parmi le chargement. Une campagne de pêche similaire fut reproduite en juillet de l'année suivante. Dans toutes ces expéditions de pêche, le maître apparaît comme patron du navire. La trajectoire d'une autre nef, La Juana (la Jeanne) de Capbreton, commandée par Esteban de Bayona, est très semblable. En janvier 1569, Auger de Barcos, marchand de Bayonne et propriétaire du bâtiment, assura sa coque pour aller de Bayonne à Séville. En juillet de cette même année, ledit Auger, qui était aussi agent d'assurances, contracta une police pour couvrir le voyage de Terre-Neuve à Bayonne avec le poisson et les graisses. À la fin de 1569, La Juana prit la mer avec de la résine et du fer à destination de Nantes, puis rejoignit le Canada. En mai 1570, la nef, dûment assurée, était de retour de la pêche à la morue. En août, son propriétaire fit charger du brai et de la résine pour joindre Bordeaux à Anvers; au voyage de retour, le navire embarqua des marchandises diverses. À la fin de 1570, après avoir été vendu à Mingot de Biarritz, il fut assuré pour le compte de marchands de Bayonne afin de transporter, de ce port à celui de Lisbonne, du brai et de la résine; il en rapporta du sucre et des épices.

Le San Juan (Saint-Jean), galion de Laredo, avait pour maîtres les frères Sebastián et Francisco de Uro, et pour patrons Juan de Alvarado, habitant de Colindres, et Pedro de Uro, habitant de Laredo. Ce vaisseau fut spécialement employé pour le commerce international de laine. En 1566, il conduisit des sacs de laine appartenant à divers éleveurs de Nájera et d'Ezcaray, de Deva à Bruges. Pendant l'hiver de 1569-1570, il fit partie d'une flotte composée de six bateaux espagnols et de deux hourques de Zélande, qui transporta des sacs de laine du port de Santander à Rouen et à Bruges. Sa cargaison, propriété de plusieurs marchands de Burgos, fut assurée pour 10000 ducats. En 1571 et 1572, il participa à deux expéditions comparables entre Santander et Bruges. Bien qu'il fût utilisé spécialement pour le transport de la laine, ses armateurs pouvaient l'employer pour d'autres types de trajets. En mars 1569, ils assurèrent pour 1140 ducats sa coque et son équipement naval pour l'expédier vers les bancs morutiers de Terre-Neuve. 
Il fit le voyage en compagnie d'un galion de Laredo nommé "San Miguel " (Saint-Michel) et commandé par Juan del Hoyo Llanes.

Le meilleur exemple de l'usage pluriel et indéterminé des navires du $\mathrm{XvI}^{\mathrm{e}}$ siècle est celui de la "zabra " de Deva, La Magdalena (la Madeleine), commandée par Martín de Zumeta et Domingo de Gárate, qui étaient aussi ses propriétaires. En 1567, elle apparaît dans les polices de Burgos chargée de fers, propriété de Martín López de Isasi de Eibar et de Martín de Unamuno de Plasencia de las Armas, marchandises qu'elle devait conduire de Deva à Séville. En novembre 1568, Andrés de Berastegui de Elorrio assura sa cargaison - composée de fer, d'acier et de ferrures - pour une valeur de 800 ducats. Le voyage consistait à relier Castrourdiales à Lisbonne. En janvier 1569, le bateau revenait à Saint-Sébastien avec sa cargaison d'épices et de cotons, le tout couvert par une police de 700 ducats contractée par différents marchands espagnols résidant à Lisbonne. En mars de cette même année, ses patrons décidèrent de l'expédier pour la pêche à la morue à Terre-Neuve, assurant pour cela sa carcasse et ses vivres à hauteur de 350 ducats. De retour au début de l'automne, sa coque fut réassurée, dès octobre, pour le transport entre Deva et Anvers de barriques de graisse appartenant à Martín López de Isasi (un personnage très souvent cité dans les documents); ces produits provenaient vraisemblablement de la campagne canadienne précédente. Au début de l'année 1570, La Magdalena réapparaît, commandée par Domingo de Gárate et en route pour Séville, avec des fers et des armes de différents marchands de Guipúzcoa. Pendant le printemps et l'été suivants, ses propriétaires décident de l'envoyer de Deva à Bruges, sous les ordres de Tomás de Arrieta, chargée de sacs de laine, propriété de divers éleveurs de Los Cameros, Logroño, Vitoria, Estella, Pamplona et Tudela. Ces derniers assurèrent la cargaison pour 5432,5 ducats. Le reste de l'année paraît inactif, jusqu'en février 1571 où divers consignataires de Burgos, Bilbao, Pamplona et Eibar assurèrent des sacs de laine et des graisses de baleine pour que le maître et propriétaire, Martín de Zumeta, les transporte de Deva à Bruges et à Anvers. Cette expédition devait également faire escale à Bordeaux. La date de son retour est indéterminée. Toutefois, en mai de cette année-là, plusieurs marchands d'Eibar assurèrent un autre chargement de fers et de lingeries qu'ils expédiaient de Deva à Séville. Le maître de la "zabra " était alors Joaquín de Retes. Pendant l'hiver, le navire, désormais sous le commandement de Domingo de Gárate, participa de nouveau à la flotte lainière qui reliait Bruges depuis Deva. Le transport lainier se reproduisit en octobre 1572, cette fois à destination de Nantes et avec Tomás de Arrieta comme maître. Au final, notre documentation - qui n'est pas censée couvrir la totalité de l'activité du navire, rappelons-le - rend compte des multiples usages faits de la "zabra " tout au long de ces cinq années. Elle fut fondamentalement destinée au commerce international, mais ses propriétaires ne dédaignèrent pas de l'employer pour la pêche à Terre-Neuve. 
En conclusion, nous appuyant sur un échantillon significatif de contrats d'assurance maritime, et notamment sur quelques exemples probants, nous avons pu mettre en lumière la pluralité des usages qui étaient faits des flottes espagnoles, portugaises et françaises au XVI ${ }^{\mathrm{e}}$ siècle. Les navires étaient tout autant destinés à la pêche hauturière, au commerce et au transport international. Aucune spécialisation des galions et des " zabras " n'apparaît nettement dans la documentation de Burgos. Au gré des besoins des maîtres et des propriétaires ainsi que des circonstances économiques et politiques, un même bâtiment pouvait servir de bateau de pêche, de navire de charge ou de vaisseau de guerre. Il était seulement nécessaire, avant chaque expédition, de revêtir l'embarcation des équipements appropriés à son usage du moment. La " pluriactivité " des moyens navals ressortissait à la nécessité de rentabiliser l'investissement de l'armateur d'une part, à celle de financer l'expédition de pêche d'autre part. De ce point de vue, il apparaît clairement que la pêche à Terre-Neuve et le commerce international étaient des activités économiques totalement complémentaires au XVI ${ }^{\mathrm{e}}$ siècle.

\section{Annexe 1 - Contrats d'assurances de Burgos relatifs à la pêche à Terre-Neuve}

\begin{tabular}{|c|c|c|c|c|c|c|c|c|}
\hline & \multicolumn{2}{|c|}{ Morue } & \multicolumn{2}{c|}{ Baleine } & \multicolumn{2}{c|}{ Inconnu } & \multicolumn{2}{c|}{ TOTAL } \\
\hline Années & POLICES & DUCATS & POLICES & DUCATS & POLICES & DUCATS & POLICES & DUCATS \\
\hline 1565 & & & 26 & 12030 & & & 26 & 12030 \\
\hline 1566 & 8 & 5500 & 1 & 100 & 2 & 1000 & 11 & 6600 \\
\hline 1567 & 2 & 400 & 6 & 4900 & 2 & 2000 & 10 & 7300 \\
\hline 1568 & 22 & 8040 & 38 & 26200 & 2 & 800 & 62 & 35040 \\
\hline 1569 & 56 & 21770 & 12 & 7400 & 1 & 800 & 69 & 29970 \\
\hline 1570 & 47 & 17855 & 15 & 10610 & 4 & 1900 & 66 & 30365 \\
\hline 1571 & 28 & 9970 & 21 & 21130 & 4 & 2610 & 53 & 33710 \\
\hline 1572 & 48 & 13584 & 41 & 32544 & 10 & 2830 & 99 & 48958 \\
\hline 1573 & 2 & 1500 & 1 & 500 & & & 3 & 2000 \\
\hline 1582 & 3 & 1400 & & & & & 3 & 1400 \\
\hline 1584 & 3 & 1300 & 1 & 900 & & & 4 & 2200 \\
\hline 1585 & 5 & 1650 & & & & & 5 & 1650 \\
\hline 1586 & & & & & 1 & 400 & 1 & 400 \\
\hline 1590 & & & 1 & 550 & & & 1 & 550 \\
\hline 1592 & & & 1 & 500 & & & 1 & 500 \\
\hline 1615 & & & & & 1 & 1300 & 1 & 1300 \\
\hline Total & 224 & 82969 & 164 & 117364 & 27 & 13640 & 415 & 213973 \\
\hline
\end{tabular}




\section{Annexe 2 - Origine des navires assurés à Burgos pour des expéditions vers Terre-Neuve}

\begin{tabular}{|c|c|c|c|c|c|c|c|c|c|c|c|c|c|c|c|c|c|c|}
\hline$\frac{d}{\tilde{\theta}}$ & $\begin{array}{l}\text { 능 } \\
\text { 늠 }\end{array}$ & $\begin{array}{l}\mathscr{0} \\
\stackrel{2}{2}\end{array}$ & $\begin{array}{l}\text { ڤ్ } \\
\text { 늄 }\end{array}$ & $\begin{array}{l}\infty \\
0 \\
10\end{array}$ &  & 욤 & $\underset{5}{5}$ & ำ & $\begin{array}{l}\stackrel{2}{10} \\
\stackrel{2}{\sim}\end{array}$ & 点 & 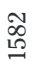 & 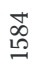 & $\begin{array}{l}\stackrel{1}{\infty} \\
\stackrel{1}{\Omega}\end{array}$ & $\begin{array}{l}\infty \\
\infty \\
10\end{array}$ & 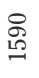 & 今ి & $\frac{10}{6}$ & స్తే \\
\hline \multicolumn{19}{|l|}{ Localités } \\
\hline Aveiro & & & & & & & & & & & & & 1 & & & & & 1 \\
\hline Avilés & & & & & 3 & 1 & & & & & & & & & & & & 4 \\
\hline Baracaldo & & & & & & & & 1 & & & & & & & & & & 1 \\
\hline Bayonne & & & & 3 & 4 & 2 & & 1 & 1 & & & & & & & & & 11 \\
\hline Bermeo & & & & & & & & 1 & & & & & & & & & & 1 \\
\hline Bilbao & 5 & 2 & & 2 & 1 & 1 & 2 & 3 & & & & 1 & 1 & & & & 1 & 19 \\
\hline Burdeos & & & & & 1 & & & 1 & & & & & & & & & & 2 \\
\hline Capbreton & & & & & 1 & 1 & & & & & & & & & & & & 2 \\
\hline Castrourdiales & & & & & & & & 2 & & & & & & & & & & 2 \\
\hline Ciboure & & & 1 & & 1 & 4 & 1 & 3 & & & & & 1 & & 1 & & & 12 \\
\hline Colindres & & & & & & & & 1 & & & & & & & & & & 1 \\
\hline Deva & 2 & 4 & 3 & 5 & 5 & 2 & 4 & 9 & & & & & & & & & & 34 \\
\hline Fuenterrabía & & & & & & 3 & 1 & & 2 & & & & & & & & & 6 \\
\hline Guetaria & & & & & & & & & & & & 1 & & & & & & 1 \\
\hline Laredo & & 1 & & 1 & 4 & 1 & 3 & 2 & & & 1 & & & & & & & 13 \\
\hline Lequéitio & & & & & & 2 & 1 & 5 & & 1 & & & & & & & & 9 \\
\hline Lezo & & & & & & & 1 & & & & & & & & & & & 1 \\
\hline Marquina & & & & & & & 1 & & & & & & & & & & & 1 \\
\hline Motrico & & & & 2 & 2 & & & & & & & & & 1 & & & & 5 \\
\hline Ondárroa & & 1 & & & 1 & & 2 & 2 & 1 & & & & & & & & & 7 \\
\hline Orio & & & & 1 & 1 & 2 & 1 & 2 & & & & & & & & & & 7 \\
\hline Pasajes & 1 & 1 & & 1 & 1 & 1 & 1 & 2 & & & & & & & & & & 8 \\
\hline Portugalete & 2 & & & & & 2 & & 4 & & & 1 & 1 & & & & & & 10 \\
\hline Rentería & & & & & & 3 & 4 & & & & & & & & & & & 7 \\
\hline $\begin{array}{l}\text { Saint-Jean-de- } \\
\text { Luz }\end{array}$ & & & & 6 & 5 & 4 & 1 & 2 & & & & & & & 1 & & & 19 \\
\hline San Sebastián & & & 1 & 6 & 5 & 6 & 11 & 17 & & & & & & & & 1 & & 47 \\
\hline Sevilla & & & & & & 1 & & & & & & & & & & & & 1 \\
\hline $\begin{array}{l}\text { Viana do } \\
\text { Castelo }\end{array}$ & & & & 3 & 3 & 1 & 4 & & & & & & & & & & & 11 \\
\hline Zarauz & & & & & & & & 2 & & & & & & & & & & 2 \\
\hline Zumaya & & & & 1 & 1 & & 1 & 3 & & & & & & & & & & 6 \\
\hline $\begin{array}{l}\text { origine } \\
\text { connue : total }\end{array}$ & 10 & 9 & 5 & 31 & 39 & 37 & 39 & 63 & 4 & 1 & 2 & 3 & 3 & 1 & 2 & 1 & 1 & 251 \\
\hline $\begin{array}{l}\text { origine incon- } \\
\text { nue }\end{array}$ & 2 & & & & 1 & & 4 & 4 & & & & & 1 & & & & & 12 \\
\hline Total & 12 & 9 & 5 & 31 & 40 & 37 & 43 & 67 & 4 & 1 & 2 & 3 & 4 & 1 & 2 & 1 & 1 & 263 \\
\hline
\end{tabular}




\section{Annexe 3 - Valeur par localité des contrats d'assurance pour la pêche à Terre-Neuve}

\begin{tabular}{|c|c|}
\hline Localité & Ducats \\
\hline Saint Sébastien & 47839 \\
\hline Deva & 23765 \\
\hline Bilbao & 15800 \\
\hline Rentería & 12850 \\
\hline Eibar & 12050 \\
\hline Saint Jean de Luz & 10350 \\
\hline Desconocido & 8335 \\
\hline Bayonne & 7950 \\
\hline Laredo & 6920 \\
\hline Portugalete & 5200 \\
\hline Pasajes & 4800 \\
\hline Lequeitio & 4750 \\
\hline Ondárroa & 4600 \\
\hline Marquina & 4400 \\
\hline Zumaya & 4370 \\
\hline Avilés & 3800 \\
\hline Orio & 3800 \\
\hline Motrico & 3650 \\
\hline Guetaria & 3440 \\
\hline Viana do Castelo & 3160 \\
\hline Fuenterrabía & 3100 \\
\hline Bordeaux & 2509 \\
\hline Ciboure & 1500 \\
\hline Baracaldo & 1500 \\
\hline Vitoria & 1300 \\
\hline
\end{tabular}

\begin{tabular}{|c|c|}
\hline Localité & Ducats \\
\hline Colindres & 1250 \\
\hline Azpeitia & 1200 \\
\hline Mondragón & 1000 \\
\hline Nantes & 1000 \\
\hline Oñate & 1000 \\
\hline $\mathrm{Ea}$ & 1000 \\
\hline Castrourdiales & 760 \\
\hline Seville & 550 \\
\hline Zarauz & 500 \\
\hline Azcoitia & 500 \\
\hline Ermua & 500 \\
\hline Carasa & 400 \\
\hline Santoña & 400 \\
\hline Puebla del Dean & 300 \\
\hline Beranguelua & 300 \\
\hline Tolosa & 250 \\
\hline Elgoibar & 250 \\
\hline Bermeo & 225 \\
\hline Aveiro & 200 \\
\hline Lezo & 200 \\
\hline Guecho & 150 \\
\hline Porto & 150 \\
\hline Elorrio & 100 \\
\hline Lisbonne & 50 \\
\hline Total & 213973 \\
\hline
\end{tabular}




\section{Annexe 4 - La complémentarité entre la pêche à Terre-Neuve et le commerce international (selon les polices d'assurance maritimes enregistrées à Burgos, 1565-1591)}

\begin{tabular}{|c|c|c|c|c|}
\hline Navire & Localité & Maître & Année & Itinéraire \\
\hline \multirow[t]{2}{*}{ San Nicolás } & \multirow[t]{2}{*}{ Bilbao } & \multirow[t]{2}{*}{$\begin{array}{l}\text { Lope de la } \\
\text { Sierra }\end{array}$} & 1565 & $\begin{array}{l}\text { Bilbao - Terre-Neuve } \\
\text { - Portugalete }\end{array}$ \\
\hline & & & 1568 & Bilbao - Anvers \\
\hline \multirow[t]{4}{*}{ La Trinidad } & \multirow[t]{4}{*}{ Pasajes } & \multirow[t]{4}{*}{ Juan de Navejas } & 1565 & $\begin{array}{l}\text { Pasajes - Terre-Neuve } \\
\text { - Pasajes }\end{array}$ \\
\hline & & & 1571 & $\begin{array}{l}\text { Pasajes - Terre-Neuve } \\
\text { - Pasajes }\end{array}$ \\
\hline & & & 1571 & Pasajes - Bruges \\
\hline & & & 1572 & Pasajes - Bruges \\
\hline \multirow[t]{5}{*}{$\mathrm{N}^{\mathrm{a}} \mathrm{S}^{\mathrm{a}}$ de la Concepción } & \multirow[t]{5}{*}{ Portugalete } & \multirow[t]{5}{*}{$\begin{array}{l}\text { Juan de Mon- } \\
\text { tellano }\end{array}$} & 1565 & Bilbao - Terre-Neuve \\
\hline & & & 1568 & Bilbao - Anvers \\
\hline & & & 1570 & Bilbao - Bruges \\
\hline & & & 1571 & Bilbao - Bruges \\
\hline & & & 1572 & Bilbao - Anvers \\
\hline \multirow[t]{2}{*}{ San Miguel } & \multirow[t]{2}{*}{ Deva } & \multirow[t]{2}{*}{$\begin{array}{l}\text { Domingo de } \\
\text { Gorozica }\end{array}$} & 1566 & Deva - Séville \\
\hline & & & 1566 & Guetaria - Terre-Neuve \\
\hline Santa Lucía & Deva & $\begin{array}{l}\text { Juan de Irraza- } \\
\text { zabal }\end{array}$ & 1566 & $\begin{array}{l}\text { Guetaria - La Rochelle } \\
\text { - Terre-Neuve - Guetaria }\end{array}$ \\
\hline \multicolumn{2}{|l|}{ La Catalina } & $\begin{array}{l}\text { Pedro de Zuaz- } \\
\text { nabar }\end{array}$ & 1566 & $\begin{array}{l}\text { Pasajes - La Rochelle } \\
\text { - Terre-Neuve - La Ro- } \\
\text { chelle }\end{array}$ \\
\hline San Buenaventura & Pasajes & Juan de Lacón & 1566 & $\begin{array}{l}\text { La Rochelle - Terre- } \\
\text { Neuve - Pasajes }\end{array}$ \\
\hline \multirow[t]{4}{*}{ San Vicente } & \multirow[t]{4}{*}{ Bilbao } & \multirow[t]{4}{*}{ Juan de Beurco } & 1566 & $\begin{array}{l}\text { Bermeo - Terre-Neuve } \\
\text { - Bermeo }\end{array}$ \\
\hline & & & 1570 & Bilbao - Aveiro \\
\hline & & & 1572 & $\begin{array}{l}\text { Bilbao - Portugal } \\
\text { - Terre-Neuve - Bilbao }\end{array}$ \\
\hline & & & 1572 & $\begin{array}{l}\text { Castrourdiales - Terre- } \\
\text { Neuve }\end{array}$ \\
\hline \multirow[t]{2}{*}{ San Juan } & \multirow[t]{2}{*}{$\begin{array}{l}\text { St-Sébas- } \\
\text { tien }\end{array}$} & \multirow[t]{2}{*}{ Juan de Bora } & 1567 & $\begin{array}{l}\text { Pasajes - Terre-Neuve } \\
\text { - Pasajes }\end{array}$ \\
\hline & & & 1572 & Pasajes - Bruges \\
\hline \multirow[t]{2}{*}{ La Concepción } & \multirow[t]{2}{*}{ Bilbao } & \multirow[t]{2}{*}{$\begin{array}{l}\text { Iñigo de Ibár- } \\
\text { tola }\end{array}$} & 1567 & $\begin{array}{l}\text { Guetaria - Terre-Neuve } \\
\text { - Deva }\end{array}$ \\
\hline & & & 1568 & $\begin{array}{l}\text { Portugalete - Nantes } \\
\text { - Terre-Neuve - Portu- } \\
\text { galete }\end{array}$ \\
\hline
\end{tabular}


La pêche à Terre-Neuve et le commerce international

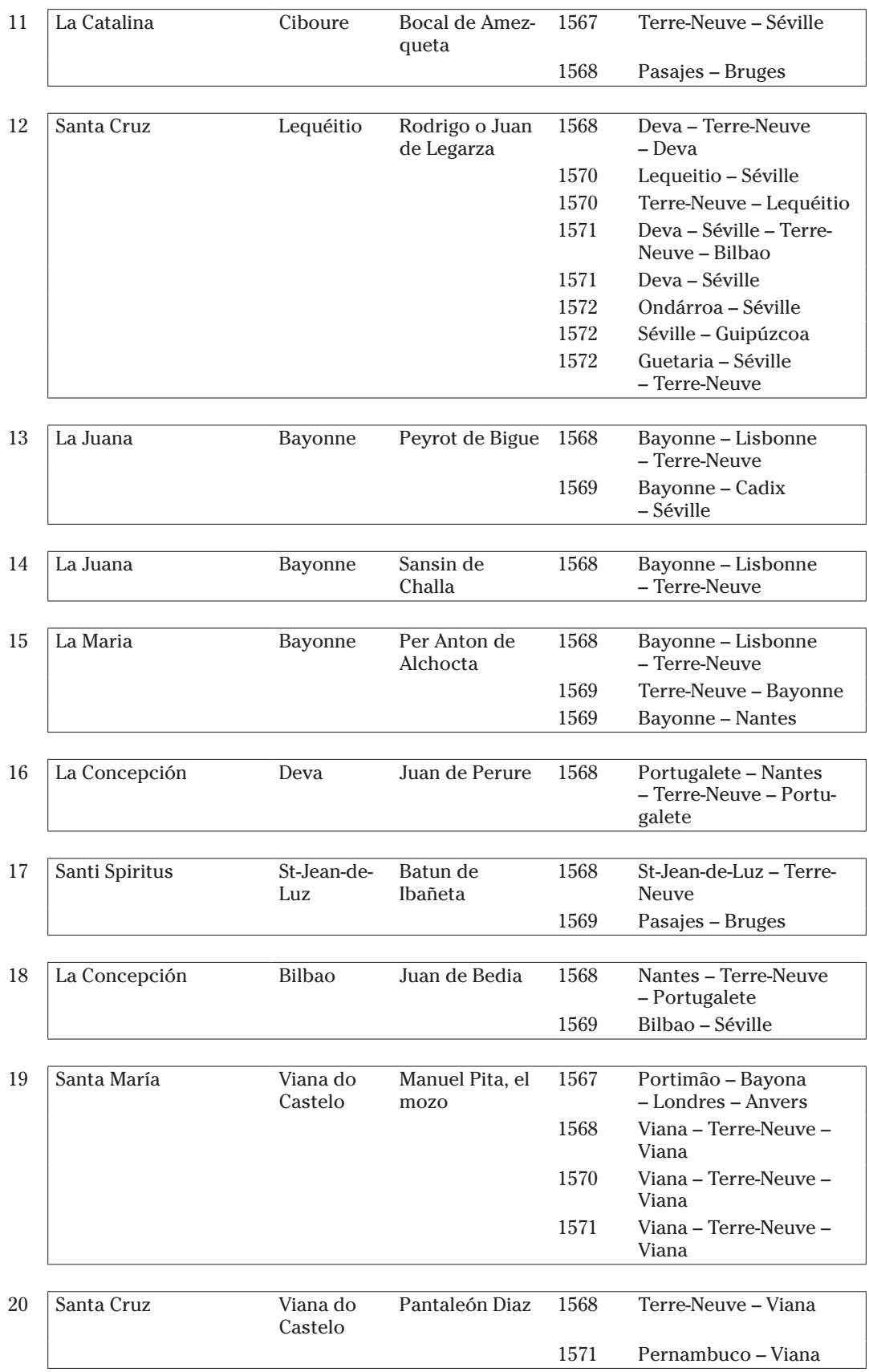




\begin{tabular}{|c|c|c|c|c|c|}
\hline 21 & La Buena Ventura & $\begin{array}{l}\text { St-Jean-de- } \\
\text { Luz }\end{array}$ & $\begin{array}{l}\text { Juan y Martín } \\
\text { de Hoviaga }\end{array}$ & $\begin{array}{l}1568 \\
1568\end{array}$ & $\begin{array}{l}\text { St-Jean-de-Luz - Nantes } \\
\text { Pasajes - Terre-Neuve }\end{array}$ \\
\hline 22 & La María & Deva & Juan de Espilla & $\begin{array}{l}1568 \\
1572\end{array}$ & $\begin{array}{l}\text { Pasajes - Terre-Neuve } \\
\text { - Pasajes } \\
\text { Laredo - Bruges }\end{array}$ \\
\hline \multirow[t]{7}{*}{23} & \multirow[t]{7}{*}{ La María } & \multirow[t]{7}{*}{$\begin{array}{l}\text { St-Sébas- } \\
\text { tien }\end{array}$} & \multirow[t]{7}{*}{$\begin{array}{l}\text { Marques de } \\
\text { Orayn }\end{array}$} & 1567 & Pasajes - La Esclusa \\
\hline & & & & 1568 & St-Sébastien - Bruges \\
\hline & & & & 1568 & $\begin{array}{l}\text { St-Sébastien - Terre- } \\
\text { Neuve - St-Sébastien }\end{array}$ \\
\hline & & & & 1569 & $\begin{array}{l}\text { Terre-Neuve - St-Sé- } \\
\text { bastien }\end{array}$ \\
\hline & & & & 1570 & $\begin{array}{l}\text { St-Sébastien - Terre- } \\
\text { Neuve }\end{array}$ \\
\hline & & & & 1571 & $\begin{array}{l}\text { St-Sébastien - Terre- } \\
\text { Neuve }\end{array}$ \\
\hline & & & & 1572 & $\begin{array}{l}\text { St-Sébastien - Terre- } \\
\text { Neuve }\end{array}$ \\
\hline \multirow[t]{3}{*}{24} & \multirow[t]{3}{*}{ Espiritu Santo } & \multirow[t]{3}{*}{$\begin{array}{l}\text { Viana do } \\
\text { Castelo }\end{array}$} & \multirow[t]{3}{*}{$\begin{array}{l}\text { Melchor } \\
\text { Mendes }\end{array}$} & 1568 & Terre-Neuve - Viana \\
\hline & & & & 1571 & Viana - Pernambuco \\
\hline & & & & 1572 & Pernambuco - Viana \\
\hline \multirow[t]{3}{*}{25} & \multirow[t]{3}{*}{ La Buena Ventura } & \multirow[t]{3}{*}{$\begin{array}{l}\text { St-Jean-de- } \\
\text { Luz }\end{array}$} & \multirow[t]{3}{*}{$\begin{array}{l}\text { Lorenzo de } \\
\text { Lizaurdi }\end{array}$} & 1567 & St-Jean-de-Luz - Bruges \\
\hline & & & & 1568 & St-Jean-de-Luz - Bruges \\
\hline & & & & 1568 & Terre-Neuve - Pasajes \\
\hline \multirow[t]{2}{*}{26} & \multirow[t]{2}{*}{$\begin{array}{l}\text { La María de San } \\
\text { Vicente }\end{array}$} & \multirow[t]{2}{*}{$\begin{array}{l}\text { St-Jean-de- } \\
\text { Luz }\end{array}$} & \multirow[t]{2}{*}{$\begin{array}{l}\text { Domingo de } \\
\text { Zubirain }\end{array}$} & 1568 & $\begin{array}{l}\text { Terre-Neuve - St-Jean- } \\
\text { de-Luz }\end{array}$ \\
\hline & & & & 1571 & Bilbao - Rouen \\
\hline \multirow[t]{2}{*}{27} & \multirow[t]{2}{*}{ La María } & \multirow[t]{2}{*}{ Bayonne } & \multirow[t]{2}{*}{$\begin{array}{l}\text { Laurens y Jua- } \\
\text { not de Arroseta }\end{array}$} & 1569 & $\begin{array}{l}\text { Bayonne - Lisbonne } \\
\text { - Terre-Neuve - Bayonne }\end{array}$ \\
\hline & & & & 1570 & Terre-Neuve - Bordeaux \\
\hline \multirow[t]{2}{*}{28} & \multirow[t]{2}{*}{ San Bartolomé } & \multirow[t]{2}{*}{ Ondárroa } & \multirow[t]{2}{*}{$\begin{array}{l}\text { Ochoa de } \\
\text { Gaviola }\end{array}$} & 1569 & $\begin{array}{l}\text { Ondárroa - Séville } \\
\text { - Terre-Neuve - On- } \\
\text { dárroa }\end{array}$ \\
\hline & & & & 1570 & Deva - Séville \\
\hline \multirow[t]{4}{*}{29} & La Trinidad & Zumaya & $\begin{array}{l}\text { Baltasar de } \\
\text { Orio }\end{array}$ & 1567 & Zumaya-Séville \\
\hline & & & & 1568 & Zumaya - Séville \\
\hline & & & & 1569 & Zumaya - Séville \\
\hline & & & & 1569 & $\begin{array}{l}\text { Séville - Terre-Neuve } \\
\text { - Guetaria }\end{array}$ \\
\hline 30 & Santiago & $\begin{array}{l}\text { St-Sébas- } \\
\text { tien }\end{array}$ & $\begin{array}{l}\text { Miguel de } \\
\text { Santiago }\end{array}$ & 1569 & $\begin{array}{l}\text { St-Sébastien - Lisbonne } \\
\text { - Terre-Neuve - St-Sé- } \\
\text { bastien }\end{array}$ \\
\hline & & & & 1572 & Pasajes - Séville \\
\hline
\end{tabular}


La pêche à Terre-Neuve et le commerce international

\begin{tabular}{|c|c|c|c|c|c|}
\hline \multirow[t]{3}{*}{31} & \multirow[t]{3}{*}{ Santa Catalina } & \multirow[t]{3}{*}{$\begin{array}{l}\text { St-Sébas- } \\
\text { tien }\end{array}$} & \multirow[t]{3}{*}{ Martín Cardel } & 1569 & $\begin{array}{l}\text { St-Sébastien - Terre- } \\
\text { Neuve }\end{array}$ \\
\hline & & & & 1571 & Pasajes - Séville \\
\hline & & & & 1572 & Pasajes - Séville \\
\hline \multirow[t]{3}{*}{32} & \multirow[t]{3}{*}{ Santa María } & \multirow[t]{3}{*}{$\begin{array}{l}\text { St-Sébas- } \\
\text { tien }\end{array}$} & $\begin{array}{l}\text { Martín Sanz de } \\
\text { Larrea }\end{array}$ & 1567 & St-Sébastien - Séville \\
\hline & & & & 1569 & $\begin{array}{l}\text { St-Sébastien - Lisbonne } \\
\text { - Terre-Neuve - St-Sé- } \\
\text { bastien }\end{array}$ \\
\hline & & & & 1569 & $\begin{array}{l}\text { Terre-Neuve - St-Sé- } \\
\text { bastien }\end{array}$ \\
\hline \multirow[t]{11}{*}{33} & \multirow[t]{11}{*}{ La Magdalena } & \multirow[t]{11}{*}{ Deva } & $\begin{array}{l}\text { Martín de } \\
\text { Zumeta }\end{array}$ & 1567 & Deva - Séville \\
\hline & & & & 1568 & $\begin{array}{l}\text { Castrourdiales - Lis- } \\
\text { bonne }\end{array}$ \\
\hline & & & & 1569 & Lisbonne - St-Sébastien \\
\hline & & & & 1569 & $\begin{array}{l}\text { Deva - Terre-Neuve } \\
\text { - Deva }\end{array}$ \\
\hline & & & & 1569 & Deva - Bruges/Anvers \\
\hline & & & & 1570 & Deva - Séville \\
\hline & & & & 1570 & Deva-Bruges \\
\hline & & & & 1571 & $\begin{array}{l}\text { Deva - Bordeaux } \\
\text { - Bruges/Anvers }\end{array}$ \\
\hline & & & & 1571 & Deva - Séville \\
\hline & & & & 1571 & Deva - Bruges \\
\hline & & & & 1572 & Deva - Nantes \\
\hline \multirow[t]{4}{*}{34} & \multirow[t]{4}{*}{ La María } & \multirow{4}{*}{$\begin{array}{l}\text { St-Jean-de- } \\
\text { Luz }\end{array}$} & $\begin{array}{l}\text { Juan Beltrán de } \\
\text { Echegaray }\end{array}$ & 1569 & Pasajes - Bruges \\
\hline & & & & 1569 & $\begin{array}{l}\text { St-Jean-de-Luz - La Baie } \\
\text { - Terre-Neuve }\end{array}$ \\
\hline & & & & 1570 & $\begin{array}{l}\text { Terre-Neuve - St-Jean- } \\
\text { de-Luz }\end{array}$ \\
\hline & & & & 1571 & Bordeaux - Terre-Neuve \\
\hline \multirow[t]{2}{*}{35} & \multirow[t]{2}{*}{ San Miguel } & \multirow[t]{2}{*}{ Santoña } & Juan del Hoyo & 1569 & Santoña - Terre-Neuve \\
\hline & & & & 1582 & Laredo-Rouen \\
\hline \multirow[t]{5}{*}{36} & \multirow[t]{5}{*}{ San Juan } & \multirow[t]{5}{*}{ Laredo } & $\begin{array}{l}\text { Sebastián y } \\
\text { Francisco de } \\
\text { Uro }\end{array}$ & 1566 & Deva-Bruges \\
\hline & & & & 1569 & $\begin{array}{l}\text { Laredo - Terre-Neuve } \\
\text { - Laredo }\end{array}$ \\
\hline & & & & 1570 & $\begin{array}{l}\text { Santander - Rouen } \\
\text { - Bruges }\end{array}$ \\
\hline & & & & 1571 & Santander - Bruges \\
\hline & & & & 1572 & Laredo - Bruges \\
\hline \multirow[t]{5}{*}{37} & \multirow[t]{5}{*}{ San Nicolás } & \multirow[t]{5}{*}{ Motrico } & \multirow[t]{5}{*}{$\begin{array}{l}\text { Juan Martinez } \\
\text { de Amezquita }\end{array}$} & 1569 & $\begin{array}{l}\text { Motrico - Terre-Neuve } \\
\text { - Motrico }\end{array}$ \\
\hline & & & & 1571 & Deva - Bruges \\
\hline & & & & 1571 & Motrico - Séville \\
\hline & & & & 1572 & Deva - Bruges \\
\hline & & & & 1572 & Deva - Séville \\
\hline
\end{tabular}




\begin{tabular}{|c|c|c|c|c|c|}
\hline 38 & $\begin{array}{l}\text { Na Señora de la } \\
\text { Concepción }\end{array}$ & Laredo & Juan Diego & $\begin{array}{l}1569 \\
1569\end{array}$ & $\begin{array}{l}\text { Santander - Rouen } \\
\text { Laredo - Terre-Neuve } \\
\text { - Laredo }\end{array}$ \\
\hline 39 & La Concepción & $\begin{array}{l}\text { Viana do } \\
\text { Castelo }\end{array}$ & $\begin{array}{l}\text { Martín Alvares } \\
\text { Sarramede }\end{array}$ & $\begin{array}{l}1569 \\
1572\end{array}$ & $\begin{array}{l}\text { Viana - Terre-Neuve } \\
\text { - Viana } \\
\text { S. Salvador de Bahía } \\
\text { - Viana }\end{array}$ \\
\hline 40 & San Cristobal & $\begin{array}{l}\text { Viana do } \\
\text { Castelo }\end{array}$ & Valentín Peres & $\begin{array}{l}1569 \\
1570 \\
\end{array}$ & $\begin{array}{l}\text { Viana - Terre-Neuve } \\
\text { - Viana } \\
\text { Olinda - Viana }\end{array}$ \\
\hline 41 & San Esteban & Orio & $\begin{array}{l}\text { Josefo de } \\
\text { Echaniz }\end{array}$ & 1570 & $\begin{array}{l}\text { Guetaria - Setúbal } \\
\text { - Terre-Neuve - Guetaria }\end{array}$ \\
\hline 42 & La Buenaventura & $\begin{array}{l}\text { Fuenter- } \\
\text { rabía }\end{array}$ & $\begin{array}{l}\text { Jerónimo de } \\
\text { Gijón y Juan } \\
\text { Surez }\end{array}$ & $\begin{array}{l}1570 \\
1571\end{array}$ & $\begin{array}{l}\text { Pasajes - Lisbonne } \\
\text { - Terre-Neuve - Pasajes } \\
\text { St-Sébastien - Terre- } \\
\text { Neuve - St-Sébastien }\end{array}$ \\
\hline 43 & La Madalena & Rentería & $\begin{array}{l}\text { Juanes de Sarai- } \\
\text { sas Gárate }\end{array}$ & 1570 & $\begin{array}{l}\text { Cadix - Terre-Neuve } \\
\text { - Cadix }\end{array}$ \\
\hline 44 & La María & Pasajes & $\begin{array}{l}\text { Domingo de } \\
\text { Villaviciosa }\end{array}$ & $\begin{array}{l}1567 \\
1569 \\
1569 \\
1572\end{array}$ & $\begin{array}{l}\text { Pasajes - Bruges } \\
\text { Pasajes - Lisbonne } \\
\text { Lisbonne - Terre-Neuve } \\
\text { - Pasajes } \\
\text { Laredo - Bruges }\end{array}$ \\
\hline 45 & La María & Bayonne & Juan Dule & $\begin{array}{l}1569 \\
1570 \\
1570\end{array}$ & $\begin{array}{l}\text { Terre-Neuve - St-Sé- } \\
\text { bastien } \\
\text { Bayonne - Rouen } \\
\text { Rouen - Bayonne }\end{array}$ \\
\hline 46 & La María & Motrico & $\begin{array}{l}\text { Juan de Olabar- } \\
\text { rieta }\end{array}$ & $\begin{array}{l}1569 \\
1571 \\
\end{array}$ & $\begin{array}{l}\text { Pasajes - Terre-Neuve } \\
\text { - Pasajes } \\
\text { Lisbonne-Pasajes }\end{array}$ \\
\hline 47 & La Juana & Capbreton & $\begin{array}{l}\text { Esteban de } \\
\text { Bayona }\end{array}$ & $\begin{array}{l}1569 \\
1569 \\
1569 \\
1570 \\
1570 \\
\\
1570\end{array}$ & $\begin{array}{l}\text { Bayonne - Séville } \\
\text { Terre-Neuve - Bayonne } \\
\text { Bayonne - Nantes } \\
\text { Terre-Neuve - Bayonne } \\
\text { Bordeaux - Anvers } \\
\text { - Bayonne } \\
\text { Bayonne - Lisbonne } \\
\text { - Bayonne }\end{array}$ \\
\hline 4 & San Nicolás & Deva & $\begin{array}{l}\text { Domingo de } \\
\text { Urdaide }\end{array}$ & $\begin{array}{l}1569 \\
1571\end{array}$ & $\begin{array}{l}\text { Terre-Neuve - Pasajes } \\
\text { Laredo - Bruges }\end{array}$ \\
\hline
\end{tabular}


La pêche à Terre-Neuve et le commerce international

\begin{tabular}{|c|c|c|c|c|c|}
\hline \multirow[t]{6}{*}{49} & \multirow[t]{6}{*}{$\begin{array}{l}N^{\mathrm{a}} \text { Señora de la } \\
\text { Concepción }\end{array}$} & \multirow[t]{6}{*}{ Portugalete } & \multirow[t]{6}{*}{$\begin{array}{l}\text { Ochoa de La } \\
\text { Sierra }\end{array}$} & 1565 & Santander - Bruges \\
\hline & & & & 1565 & L'Ecluse - Portugalete \\
\hline & & & & 1568 & Santander - Bruges \\
\hline & & & & 1569 & Anvers - Laredo \\
\hline & & & & 1570 & $\begin{array}{l}\text { Laredo - Terre-Neuve } \\
\text { - Laredo }\end{array}$ \\
\hline & & & & 1572 & Laredo - Anvers \\
\hline \multirow[t]{6}{*}{50} & \multirow[t]{6}{*}{ La Concepción } & \multirow[t]{6}{*}{ Deva } & $\begin{array}{l}\text { Domingo de } \\
\text { Ganchegui }\end{array}$ & 1569 & Deva - Lisbonne \\
\hline & & & & 1569 & Deva - Séville \\
\hline & & & & 1570 & $\begin{array}{l}\text { Deva - Séville - Terre- } \\
\text { Neuve - Séville/Deva }\end{array}$ \\
\hline & & & & 1571 & Deva - Séville \\
\hline & & & & 1571 & Séville - St-Sébastien \\
\hline & & & & 1572 & Deva - Séville \\
\hline \multirow[t]{2}{*}{51} & \multirow[t]{2}{*}{ La Concepción } & \multirow[t]{2}{*}{ Laredo } & Juan de Esca- & 1570 & Santander - Rouen \\
\hline & & & & 1570 & $\begin{array}{l}\text { Laredo - Setúbal - Terre- } \\
\text { Neuve - Laredo }\end{array}$ \\
\hline \multirow[t]{2}{*}{52} & \multirow{2}{*}{$\begin{array}{l}\text { La María de San } \\
\text { Vicente }\end{array}$} & \multirow[t]{2}{*}{ Ciboure } & Miguel de & 1569 & Bilbao-Nantes \\
\hline & & & & 1570 & Bilbao - Terre-Neuve \\
\hline \multirow[t]{5}{*}{53} & \multirow[t]{5}{*}{$\begin{array}{l}\text { Santa María de la } \\
\text { Candelaria }\end{array}$} & \multirow[t]{5}{*}{ Lequeitio } & $\begin{array}{l}\text { Juan Martínez } \\
\text { de Unda }\end{array}$ & 1570 & Lequeitio - Terre-Neuve \\
\hline & & & & 1572 & Terre-Neuve - Lequeitio \\
\hline & & & & 1572 & $\begin{array}{l}\text { Lequeitio - Setúbal/ } \\
\text { Aveiro - Terre-Neuve }\end{array}$ \\
\hline & & & & 1572 & Terre-Neuve - Lequeitio \\
\hline & & & & 1573 & Deva - Séville \\
\hline \multirow[t]{3}{*}{54} & \multirow[t]{3}{*}{ El Jesús } & \multirow[t]{3}{*}{ Pasajes } & $\begin{array}{l}\text { Vicente de } \\
\text { Echave }\end{array}$ & 1567 & Pasajes - Bruges \\
\hline & & & & 1570 & $\begin{array}{l}\text { Motrico - Lisbonne } \\
\text { - Terre-Neuve - Motrico }\end{array}$ \\
\hline & & & & 1571 & $\begin{array}{l}\text { Pasajes - Setúbal } \\
\text { - Terre-Neuve - Pasajes }\end{array}$ \\
\hline \multirow[t]{6}{*}{55} & \multirow[t]{6}{*}{ San Salvador } & \multirow[t]{6}{*}{ Rentería } & $\begin{array}{l}\text { Sebastian y Jos } \\
\text { de Zubieta }\end{array}$ & 1569 & Pasajes - Séville \\
\hline & & & & 1570 & Pasajes - Terre-Neuve \\
\hline & & & & 1570 & Terre-Neuve - Pasajes \\
\hline & & & & 1571 & $\begin{array}{l}\text { Pasajes - Terre-Neuve } \\
\text { - Pasajes }\end{array}$ \\
\hline & & & & 1571 & $\begin{array}{l}\text { Terre-Neuve - St-Sé- } \\
\text { bastien }\end{array}$ \\
\hline & & & & 1572 & Pasajes - Séville \\
\hline \multirow[t]{2}{*}{56} & \multirow[t]{2}{*}{$\begin{array}{l}\text { La María de San } \\
\text { Vicente }\end{array}$} & \multirow[t]{2}{*}{ Ciboure } & \multirow[t]{2}{*}{$\begin{array}{l}\text { Bartolomé de } \\
\text { Sarria }\end{array}$} & 1570 & $\begin{array}{l}\text { Terre-Neuve - St-Jean- } \\
\text { de-Luz }\end{array}$ \\
\hline & & & & 1571 & St-Jean-de-Luz - Bruges \\
\hline
\end{tabular}




\begin{tabular}{|c|c|c|c|c|c|}
\hline 57 & $\begin{array}{l}\text { Nuestra Señora de } \\
\text { Begoña }\end{array}$ & Portugalete & $\begin{array}{l}\text { Martín de } \\
\text { Alzaga }\end{array}$ & $\begin{array}{l}1570 \\
1570\end{array}$ & $\begin{array}{l}\text { Bilbao - Nantes } \\
\text { Terre-Neuve - Portu- } \\
\text { galete }\end{array}$ \\
\hline 58 & $\begin{array}{l}\text { Nuestra Señora de } \\
\text { Begoña }\end{array}$ & Portugalete & Lope de Berriz & $\begin{array}{l}1571 \\
1571 \\
1571 \\
\\
1572 \\
1572 \\
1591 \\
\end{array}$ & $\begin{array}{l}\text { Bilbao - Bruges } \\
\text { Bilbao - Nantes } \\
\text { Bilbao - Terre-Neuve } \\
\text { - Bilbao } \\
\text { Santander - Bruges } \\
\text { Terre-Neuve - Bilbao } \\
\text { Bilbao - Bruges }\end{array}$ \\
\hline 5 & San Miguel & Ondárroa & $\begin{array}{l}\text { Juan de la } \\
\text { Rentería }\end{array}$ & $\begin{array}{l}1569 \\
1571 \\
\end{array}$ & $\begin{array}{l}\text { Ondárroa - Cadix } \\
\text { Ondárroa - Terre-Neuve }\end{array}$ \\
\hline 60 & San Miguel & Ondárroa & Juan de Ayardia & $\begin{array}{l}1569 \\
1571 \\
1571 \\
1572 \\
\end{array}$ & $\begin{array}{l}\text { Ondárroa - Séville } \\
\text { Ondárroa - Terre-Neuve } \\
\text { Terre-Neuve - Ondárroa } \\
\text { Guetaria - Séville }\end{array}$ \\
\hline 61 & Santa María & Deva & $\begin{array}{l}\text { Domingo de } \\
\text { Vergara }\end{array}$ & $\begin{array}{l}1572 \\
1572\end{array}$ & $\begin{array}{l}\text { Deva - Séville } \\
\text { Deva - Séville - Terre- } \\
\text { Neuve - Deva }\end{array}$ \\
\hline 62 & $\begin{array}{l}\text { Nuestra Señora de } \\
\text { Begoña }\end{array}$ & Bilbao & $\begin{array}{l}\text { Ochoa de } \\
\text { Larrea }\end{array}$ & $\begin{array}{l}1570 \\
1571 \\
1572\end{array}$ & $\begin{array}{l}\text { Santander - Bruges } \\
\text { Santander - Bruges } \\
\text { Portugalete - Setúbal } \\
\text { - Terre-Neuve }\end{array}$ \\
\hline 63 & La Candelaria & Lequeitio & $\begin{array}{l}\text { Martín de } \\
\text { Beleda }\end{array}$ & 1572 & $\begin{array}{l}\text { Lequeitio - Setúbal } \\
\text { - Terre-Neuve - Le- } \\
\text { queitio }\end{array}$ \\
\hline 64 & La Trinidad & Deva & $\begin{array}{l}\text { Juan Pérez de } \\
\text { Arriola }\end{array}$ & $\begin{array}{l}1570 \\
1571 \\
1571 \\
1572\end{array}$ & $\begin{array}{l}\text { Deva - Terre-Neuve } \\
\text { - Deva } \\
\text { Deva - Bruges } \\
\text { Deva - Lisbonne } \\
\text { Deva - Terre-Neuve }\end{array}$ \\
\hline 65 & San Bartolomé & Ondárroa & $\begin{array}{l}\text { Domingo de } \\
\text { Ondárroa }\end{array}$ & $\begin{array}{l}1571 \\
1572 \\
1572 \\
1572\end{array}$ & $\begin{array}{l}\text { Ondárroa - Séville } \\
\text { Motrico - Séville - Terre- } \\
\text { Neuve - Motrico } \\
\text { Motrico - Séville } \\
\text { Séville - Motrico }\end{array}$ \\
\hline
\end{tabular}


La pêche à Terre-Neuve et le commerce international

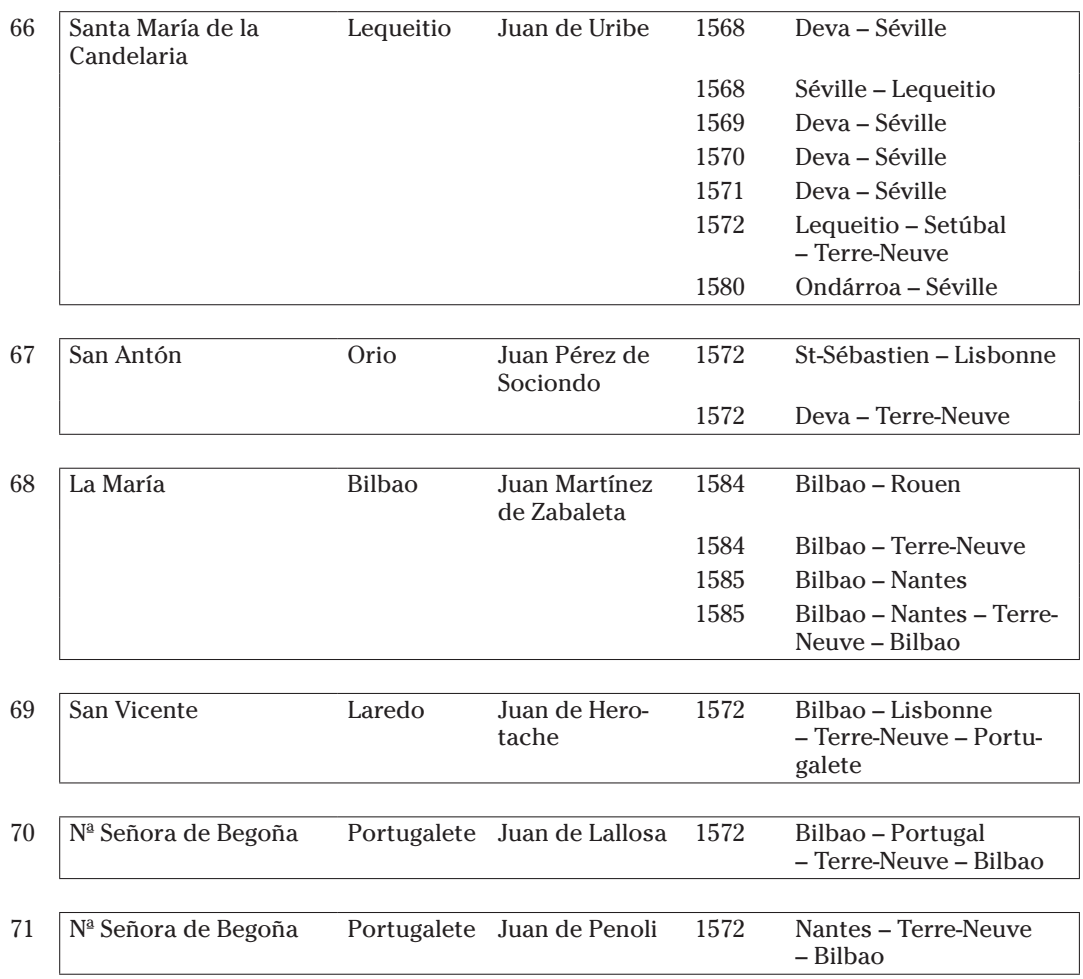




\section{RÉSUMÉ}

L'article étudie la pêche à Terre-Neuve dans la seconde moitié du $\mathrm{XVI}^{\mathrm{e}}$ siècle à partir de $\mathbf{4 1 5}$ polices d'assurance enregistrées devant le Consulat de Burgos, un des principaux centres d'assurance en Europe à cette époque. Ces documents détaillent d'une part les caractéristiques desdits voyages : prix, dangers encourus, participants, destination, routes, provenance des bateaux et des marins, etc. Ils sont à replacer parmi les 10397 polices d'assurance conservées qui permettent de reconstituer au total 4743 expéditions entre 1565 et 1619. On constate que les maîtres, les propriétaires et les équipages des navires combinaient la pêche à Terre-Neuve avec le commerce international qui formaient deux activités complémentaires, sans qu'il y ait spécialisation entre les différentes activités. Les flottes espagnoles, portugaises et françaises développaient un pluriactivité, moyen de diversifier les affaires et par voie de conséquence de répartir les risques.

\section{ABSTRACT}

This paper studies fishing in Newfoundland during the second half of the sixteenth century. It analyses 415 maritime insurance contracts, all of which were registered at the Burgos Consulate, which was then one of the major insurance centres in Spain. We analyse the main characteristics of the journeys undertaken: price, danger, function, routes, origin of ships and sailors, etc. Furthermore, the surviving documentation (10,397 contracts) also allows us to reconstruct 4,372 maritime expeditions between 1565 and 1619. These data have allowed us to observe that the masters, owners and sailors who undertook fishing expeditions to Newfoundland also engaged in international trade. Fishing and trade were complementary activities and ships did not specialise in one or the other. In the sixteenth century, the Spanish, Portuguese and French fleets were very versatile and sought to diversify their activities and, thereby, reduce risk. 